\title{
Fouilles de la cité de Taman : de l'antique Hermonassa à la Tamatarkha médiévale
}

Svetlana Il'inična Finogenova et Tat'jana Anatol'evna Il'ina

Traducteur : Fabrice Guibentif

\section{OpenEdition}

\section{Journals}

Édition électronique

URL : https://journals.openedition.org/edl/1743

DOI : $10.4000 /$ edl. 1743

ISSN : 2296-5084

\section{Éditeur}

Université de Lausanne

\section{Édition imprimée}

Date de publication : 15 mai 2019

Pagination : 285-327

ISBN : $978-2-940331-70-3$

ISSN : 0014-2026

\section{Référence électronique}

Svetlana Il'inična Finogenova et Tat'jana Anatol'evna Il'ina, « Fouilles de la cité de Taman : de l'antique Hermonassa à la Tamatarkha médiévale », Études de lettres [En ligne], 309 | 2019, mis en ligne le 15 mai 2021, consulté le 17 mai 2021. URL : http://journals.openedition.org/edl/1743 ; DOI : https:// doi.org/10.4000/edl.1743 


\section{FOUILLES DE LA CITÉ DE TAMAN : DE L'ANTIQUE HERMONASSA À LA TAMATARKHA MÉDIÉVALE}

Hermonassa est située sur la côte méridionale de la baie de Taman. Elle occupe aujourd'hui une surface de près de 16 ha répartie sur deux niveaux. Des recherches archéologiques sont actuellement menées dans la moitié ouest, déclarée protégée et libre de toute construction moderne. La ville d'Hermonassa apparaît au plus tard à la fin du $\mathrm{VI}^{\mathrm{e}}$ s. av. J.-C. et subsiste presque sans interruption durant les époques historiques successives, changeant seulement de taille et de nom. Au IVe s. av. J.-C., elle intègre l'État du Bosphore Cimmérien en même temps que la Sindiké. Durant les premiers siècles de notre ère, des liens commerciaux entre le Bosphore et les tribus alanes sont entretenus via Hermonassa. L'histoire antique de la ville d'Hermonassa s'achève avec l'arrivée des nomades. Dès le milieu du III e siècle, la ville subit l'invasion des Goths, alors que durant la seconde moitié du IV siècle, l'arrivée des Huns ne cause pas de destruction notable à la ville. L'influence de Byzance commence à se faire sentir à Hermonassa aux $\mathrm{V}^{\mathrm{e}}$ et IV $\mathrm{IV}^{\mathrm{e}}$ siècles. L'histoire médiévale de la ville de Tamatarkha débute lorsqu'elle passe sous la coupe des Khazars au VII e siècle. Il se peut que Tamatarkha ait fait partie, avec d'autres centres urbains de Tauride, du système de "dyarchie» byzantino-khazare. Ce système de rapports réciproques s'est poursuivi jusqu’au deuxième tiers du IX ${ }^{\mathrm{e}}$ siècle.

\section{Situation et sources écrites}

La cité de Taman est située sur la côte méridionale de la baie de Taman (voir la carte B, p. 22), non loin du bourg cosaque de Taman (district de Temrjuk, région de Krasnodar). Elle est associée à l'histoire de plusieurs peuples, qui l'ont chacun nommée à sa manière: les Grecs l'appelaient Hermonassa, les Khazars Matluka ou Tamatarkha, les Slaves Tmutarakan', les Polovtses Matrika ou Matarkha, les Gênois Matrega, les Turcs Taman. 
Si l'origine du nom d'Hermonassa n'est pas établie avec certitude, il en existe plusieurs versions. Selon l'une d'elles, la ville a été fondée par un certain Hermon originaire d'Ionie. Selon une autre version que l'on peut lire dans le commentaire d'Eustathe au Voyage autour du monde de Denys le Périégète, à la mort du chef de la colonie, un certain Simandre originaire de Mytilène, les rênes du pouvoir ont été reprises par sa femme, Hermonassa ${ }^{1}$.

La cité, qui existe depuis le $\mathrm{VI}^{\mathrm{e}}$ s. av. J.-C., a subsisté plus de deux mille ans, au cours desquels les frontières et les dimensions du site ont varié. Sa situation géographique avantageuse lui permettait de contrôler le passage entre la mer Noire et la mer d'Azov.

On trouve quelques rares mentions de la localisation d'Hermonassa chez les auteurs de l'Antiquité; par exemple chez Strabon:

Le navigateur qui pénètre dans le Corocondamitide [l'actuelle Baie de Taman] touche successivement Phanagorie, ville très renommée, puis Kèpoi, Hermonassa et Apatouron, sanctuaire d'Aphrodite. Deux de ces localités, Phanagorie et Kèpoi, sont bâties sur l'île précitée, à gauche quand on entre dans le lac de l'île mentionnée. Les autres villes sont à droite, de l'autre côté de l'Hypanis [l'actuel fleuve Kouban] sur le territoire de la Sindiké ${ }^{2}$.

La géographie de Taman s'est transformée au cours du temps sous l'effet de l'activité volcanique. L'archipel de l'Antiquité, constitué de multiples îles, est devenu aujourd'hui une péninsule dont le littoral a évolué et où le cours des nombreux affluents du Kouban s'est modifié. La question de la localisation de l'ancienne Hermonassa reste donc ouverte ${ }^{3}$.

La cité est située sur un plateau à deux niveaux (fig. 1). Des maisons d'habitation occupent la partie centrale. La partie nord, qui constitue un tiers du territoire du site, a été entièrement érodée par la mer, emportée dans l'effondrement des berges. Les investigations archéologiques se déroulent dans la moitié ouest - une zone s'étendant sur 25 ha déclarée protégée et libre de toute construction moderne. C'est là que sur trois

I. Evstafij, Kommentarija k zemleopisaniju Dionisija / Per. I. P. Cvetkova, p. 198.

2. Strabon XI.2.10 (traduction de F. Lasserre, Les Belles Lettres).

3. V. G. Zubarev, "Aziatskij Bospor (Tamanskij poluostrov) po dannym antičnoj pis'mennoj tradicii», p. 123; D. Kel'terbaum, D. V. Žuravlev, U. Šlotcauer, «Issledovanija v oblasti paleografii Tamanskogo poluostrova», p. 21-27. 
Fig. 1 - La cité vue depuis la mer. Photographie de Andrej Kudrjavickij et Sergej Ševčenko.

zones de fouilles distinctes (Nord [Severnyj], Haute [Nagornyj] et NordEst [Severo-Vostočnyj] la couche anthropique a été explorée depuis le niveau de circulation contemporain jusqu'à la terre d'origine (fig. 2).

La ville basse est quasi inexplorée. Trois sondages ont été pratiqués, permettant la découverte d'une couche du $\mathrm{VI}^{\mathrm{e}}$ s. av. J.-C. ${ }^{4}$. Les surfaces fouillées sont toutefois si réduites qu'on ne peut pas parler de vestiges concrets de construction. Il est possible que la ville antique se situait sur le plateau supérieur et que le plateau inférieur était une zone de parcelles suburbaines.

Le principal matériau de construction de la cité a été l'argile. Les maisons construites dans ce matériau tombant rapidement en ruine, la couche de culture du site atteint 12 à $13 \mathrm{~m}$.

Des nécropoles, fouillées dès la fin du XIX siècle (kourganes) et jusqu'à nos jours (en pleine terre), entourent la cité de Taman à l'est, au sud et à l'ouest.

4. I. B. Zeest, «Vozniknovenie i pervyj rascvet Germonassy», p. 83, fig. 1. 
288

ÉTUDES DE LETTRES 


\section{Historique des fouilles}

Malgré l'intérêt que le site a suscité aux XVIII ${ }^{\mathrm{e}}$ et XIX ${ }^{\mathrm{e}}$ siècles auprès des amateurs d'antiquités, des voyageurs et de toute sorte d'aventuriers, les recherches scientifiques systématiques n'ont commencé qu'au $\mathrm{XX}^{\mathrm{e}}$ siècle. En 1931 et 1932, Aleksandr Aleksandrovič Miller explore des secteurs des plateaux supérieur et inférieur et ébauche une stratigraphie générale de la cité 5 .

Au cours de travaux menés entre 1952 et 1971 sur la fouille Haute, Irjada Borisovna Zeest, de l'Institut d'Archéologie de l'Académie des sciences, établit la succession des couches d'occupation et met en évidence dix-huit horizons de construction ${ }^{6}$.

Des investigations dans les zones de fouille Haute et Nord sont conduites entre 1968 et 1987 sous la direction d'Anna Konstantinovna Korovina, à la tête de la mission détachée du Musée Pouchkine. On lui doit d'avoir rectifié la stratigraphie du site et établi les frontières de la ville. Une synthèse de ses recherches est publiée dans une monographie intitulée Une ville antique sur la péninsule de Taman ${ }^{7}$. Dès 1988, l'exploration des zones de fouille Haute et Nord-Est se poursuit avec Svetlana Il'inična Finogenova, qui met au jour les complexes les plus anciens, remontant au milieu du $\mathrm{VI}^{\mathrm{e}}$ s. av. J.-C. ${ }^{8}$. Les recherches sur la fouille Nord sont dirigées depuis 2006 par Tatiana Anatol'evna Il'ina. Les couches médiévales de la ville ont été explorées à la fin du XXe siècle par Ėl'mira Radifovna Ustaeva et Irina Nikolaevna Bogoslovskaja, du Musée régional de Taman. L'exploration de l'horizon médiéval sur la fouille Haute est reprise en 2008 sous la direction de Viktor Nikolaevič Čkhaidze, de l'Institut d'Archéologie de l'Académie des sciences de Russie.

5. A. A. Miller, «Tamanskaja èkspedicija Gosudarstvennoj akademii istorii material'noj kul'tury» et "Tamanskaja èkspedicija Gosudarstvennaja akademija istorii material'noj kul'tury v $1931 »$.

6. I. B. Zeest, «K voprosu o gorodskoj planirovke Germonassy», p. 54.

7. A. K. Korovina, Germonassa, p. 147.

8. S. I. Finogenova, "Germonassa». 


\section{Hermonassa aux premiers temps}

L'histoire d'Hermonassa en tant qu'établissement commercial remonte au milieu du $\mathrm{VI}^{\mathrm{e}}$ s. av. J.-C. Le peuplement du territoire s'effectuait depuis l'est vers l'ouest. Des constructions datant des premiers colons ont été mises au jour dans la zone de fouille Nord-Est ${ }^{9}$. L'une d'elles, une maison semi-enterrée d'une surface de $16 \mathrm{~m}^{2}$, a brûlé à la fin du $\mathrm{VI}^{\mathrm{e}}$ s. av. J.-C. La charpente du toit était constituée de pièces de bois équarries, tandis que les murs étaient faits de roseaux enduits d'argile. Les traces d'un four qui occupait la plus grande partie de l'espace ont été mises au jour dans la partie sud-est. À l'intérieur de la hutte et dans des fosses pratiquées à proximité, on a découvert des fragments de céramique ionienne, dont les plus anciens datent de la première moitié du VI ${ }^{\mathrm{e}} \mathrm{s}$. av. J.-C., notamment des assiettes et des coupes décorées de bandes, de cercles concentriques, de méandres et d'étoiles, ainsi que des amphores ornées de chèvres sauvages. Les vestiges de modestes constructions d'habitation avec deux poêles-braseros et des fosses domestiques ont été découverts en 1957 sur la fouille Haute ${ }^{10}$.

De multiples fragments d'amphores de Chios et de Lesbos confirment l'intensité des liens commerciaux qu'entretenait Hermonassa avec divers centres de la Méditerranée durant la seconde moitié du VI ${ }^{\mathrm{e}}$ s. av. J.-C. ${ }^{11}$.

La ville ionienne de Clazomènes fournissait, outre des céramiques de stockage et des récipients à décors d'écaille, de la céramique à décors figurés ${ }^{12}$. La plus célèbre d'entre elles est une hydrie à figures noires avec des représentations de coqs, trouvée en 1928 dans une sépulture près du bourg de Taman (fig. 3) ${ }^{13}$.

La production attique est représentée par des kylikes ornés de figures de petite taille. Parmi ceux-ci, il faut citer une coupe de Siana avec une scène d'adieu en médaillon et une scène de combat d'hoplites sur la face

9. S. I. Finogenova, "Očerki istorii Germonassy po materialam raskopok poslednikh let».

Io. I. B. Zeest, "Arkhaičeskie sloi Germonassy», fig. 17.

II. S. I. Finogenova, "K voprosu o torgovykh otnošenijakh arkhaičeskoj Germonassy", p. 91.

I2. S. I. Finogenova, «Arkhaicheskaja keramika Germonassy iz raskopok poslednikh let», p. 338, tab. 1.1-4, 12 .

I3. T. N. Knipovič, «Ionijskaja vaza s Tamanskogo poluostrova i klazomenskij stil’ v pamjatnikakh grečeskikh poselenij severnogo poberež ja Čjornogo morja». 


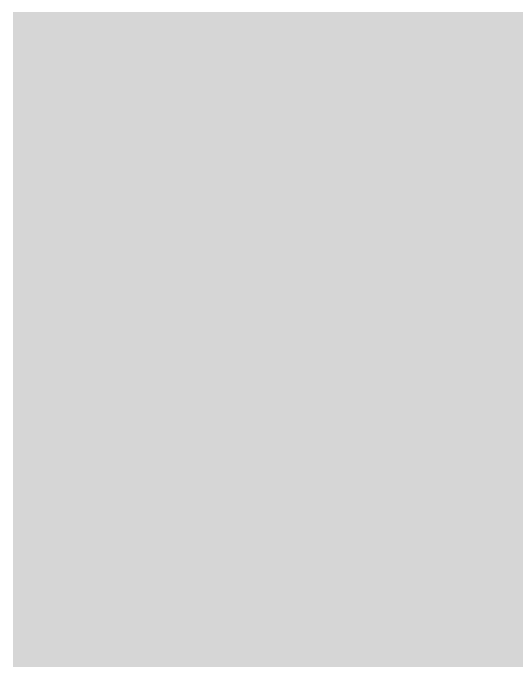

Fig. 3 - Hydrie à figures noires. Seconde moitié du VI ${ }^{\mathrm{e}}$ s. av. J.-C. Photographie de Andrej Kudrjavickij et Sergej Ševčenko. externe, datée du second quart ou du milieu du $\mathrm{VI}^{\mathrm{e}}$ s. av. J.-C. ${ }^{14}$. Une trouvaille intéressante est celle $\mathrm{du}$ fond d'un kylix à figures noires avec la Gorgone Méduse datant des années 530-520 av. J.-C. ${ }^{15}$. Il faut également porter au nombre des pièces d'importation des lécythes et des skyphoi, de piètre facture, décorés par des peintres de l'atelier d'Haimon ${ }^{16}$.

Les vases à figures rouges sont représentés par des skyphoi, des rhytons et des kylikes. L'un d'eux est orné d'une figure d'Héraclès allongé $^{17}$ (fig. 4.1-3, 5-6).

\section{Sous l'autorité des Archéanactides}

La période de la fin du VIe s. à la fin du Ve s. av. J.-C. marque l'arrivée au pouvoir de la dynastie des Archéanactides. L'urbanisation s'intensifie et les procédés architecturaux se diversifient. En 1969 ont été mis au jour sur la fouille Haute un ouvrage en maçonnerie de $5 \mathrm{~m}$ de long, ainsi qu'un socle de pierre en appareil polygonal avec des restes de brique crue $^{18}$. Sur la fouille Nord-Est, deux maisons avaient été construites à l'emplacement d'une hutte semi-enterrée. La première était composée de trois pièces; de la deuxième, seul un angle a été conservé ${ }^{19}$.

Tous les édifices étaient situés sur une ligne nord-est/sud-ouest. La ville entretenait des liens très étroits avec la mer durant les premières étapes de son développement, si bien que jusqu'au $\mathrm{IV}^{\mathrm{e}} \mathrm{s}$. av. J.-C. les rues

I4. S. I. Finogenova, «Arkhaicheskaja keramika Germonassy iz raskopok poslednikh let», p. 347 et fig. 4.

15. Ibid., p. 347 et fig. 3.3.

I6. Ibid., p. 347 et fig. 4.

I7. S. I. Finogenova, "Germonassa", p. 515, ill. 9.

I8. Ibid., p. 513.

I9. Ibid., p. 514. 
Fig. 4 - Trouvailles des couches de la période classique. Photographies de Andrej Kudrjavickij et Sergej Ševčenko. 
Fig. 5 - Bâtiment du Ve-début du IVe s. av. J.-C. Fouille Nord, vue du sud. Photographie de Andrej Kudrjavickij et Sergej Ševčenko.

et les maisons étaient orientées en direction du quai, c'est-à-dire vers le nord-est en partant des zones étudiées ${ }^{20}$.

$\mathrm{Au} \mathrm{V}^{\mathrm{e}}$ s. av. J.-C., le principal matériau de construction reste l'argile. C'est à cette période que remonte une maison avec sous-sol et murs de brique crue, d'une surface de près de $56 \mathrm{~m}^{2}$, mise au jour sur la fouille Nord-Est ${ }^{21}$. On peut supposer que les ordres architecturaux ont fait leur apparition en même temps que les édifices civils. C'est ce qu'indique la découverte d'un chapiteau ionique et un fragment d'architrave qui a pu appartenir à un temple d'Apollon ${ }^{22}$.

En 2010 a été mise au jour sur la fouille Nord la fondation d'un bâtiment composée de deux rangées de pierres avec murs de brique crue (d'une surface de $40 \mathrm{~m}^{2}$ ) (fig. 5) ${ }^{23}$. Un foyer ouvert se trouvait près du mur intérieur sud de la maison.

20. I. B. Zeest, «K voprosu o gorodskoj planirovke Germonassy», p. 54 sq.

2I. S. I. Finogenova, "Očerki istorii Germonassy po materialam raskopok poslednikh let», p. 427 sq., ill. 2.

22. G. F. Arzamanov, "Arkhaičeskaja kapitel' iz Tamani».

23. S. I. Finogenova, T. A. Il'ina, «Rezul'taty issledovanija Tamanskogo gorodišča (po materialam 2010-2013 gg.)», p. 431. 
Dans la partie sud de la même zone de fouille a été découverte une vaste tache de forme oblongue $(2,5 \times 1,2 \mathrm{~m})$, creusée dans la terre et contenant des petits éclats de charbon, des fragments de brique crue concassée, d'argile calcinée et de céramique concassée ${ }^{24}$. La destination de cette excavation n'est pas claire; dans la couche d'occupation, on a trouvé des objets de différentes époques, de la première moitié du $\mathrm{V}^{\mathrm{e}} \mathrm{s}$. au début du $\mathrm{IV}^{\mathrm{e}}$ s. av. J.-C. Dans la partie ouest du site avait été creusée une fosse s'enfonçant à une profondeur de $3 \mathrm{~m}$ dans le sol naturel. Du matériel céramique du $\mathrm{V}^{\mathrm{e}}$ s. av. J.-C. a été découvert lors de l'échantillonnage de cette structure: des fragments d'amphores de Chios, de récipients de Clazomènes, de kylikes à figures noires et d'un cratère à sujet dionysiaque, ainsi qu'une petite figurine de tortue en terre cuite de production rhodienne (fig. 4.4 et 4.11).

Ainsi, dans la partie ouest de la fouille Nord, les couches les plus anciennes datent du début ou de la première moitié du $\mathrm{V}^{\mathrm{e}} \mathrm{s}$. av. J.-C., alors que dans la partie est, elles datent de la fin du VI ${ }^{\mathrm{e}}$ s. av. J.-C. C'est là une nouvelle confirmation de l'hypothèse de I. B. Zeest et de A. K. Korovina, pour qui le début du peuplement d'Hermonassa s'est fait de l'est vers l'ouest ${ }^{25}$.

Parmi les trouvailles uniques de cette période, il faut signaler deux perles de pâte de verre en forme de tête de mouton et de démon barbu provenant de la Méditerranée orientale, un fragment de cratère à figures rouges avec une représentation de guerrier équipé d'un bouclier et tenant un casque à la main ${ }^{26}$ (fig. 4.7-10, 12-15).

Hermonassa occupe à cette époque l'une des positions les plus influentes dans le Bosphore. Denys le Périégète en fait l'égale de Phanagorie et la dit «magnifiquement construite» ${ }^{27}$. Vladimir Dmitrievič Blavatskij fait l'hypothèse qu'un membre de la lignée des Archéanactides devait vivre à Hermonassa ${ }^{28}$.

24. Ibid.

25. I. B. Zeest, "Arkhaičeskie sloi Germonassy», p. 54 sq.

26. S. I. Finogenova, T. A. Il'ina, «Rezul'taty issledovanija Tamanskogo gorodišča (po materialam 2010-2013 gg.), p. 432.

27. Voir Denys le Périégète, v. 552 dans la traduction russe établie par V. V. Latyšev.

28. V. D. Blavatskij, "Arkhaičeskij Bospor», p. 41-44. 


\section{Le règne des Spartocides}

Le statut de la ville change avec l'arrivée au pouvoir de la dynastie des Spartocides. Évoquer un déclin économique n'est probablement pas justifié, mais les couches d'occupation des IVe-III' s. av. J.-C. sont nettement inférieures aux $2 \mathrm{~m}$ de stratification de la période précédente. Les fouilles montrent que l'on commence alors à ériger des édifices monumentaux à caractère public ${ }^{29}$. L'un d'eux comportait une petite cour à péristyle ouvrant sur des locaux au nord, à l'ouest et à l'est ${ }^{30}$. Un enduit rouge, blanc et bleu couvrait les murs de certains d'entre eux. À l'intérieur, quatre œnochoés estampillées des noms des agoranomes Apollodore et Polyxène ont été récoltées, ainsi qu'un sceau d'argile avec monogramme et des monnaies de bronze. Ce sont ces trouvailles qui ont amené $\mathrm{A}$. K. Korovina à penser qu'il s'agissait là d'un prytanée ${ }^{31}$. L'édifice subsiste tout au long des IVe et III ${ }^{\mathrm{e}}$ s. av. J.-C. et subit plusieurs reconstructions avant de disparaître dans un incendie.

En 1984, la partie orientale d'une grande résidence urbaine a été mise au jour sur la fouille $\operatorname{Nord}^{32}$ (fig. 6). Il en a été conservé une surface d'environ $50 \mathrm{~m}^{2}$, pavée de fragments d'amphores produites sur l'île de Thasos, à Sinope et à Héraclée du Pont. Une rigole la traversant du nord au sud et conduisant à une cuve permettait de collecter les eaux de pluie. Au nord, le pavage allait jusqu'à une maison à sous-sol en brique crue (d'une surface de $14,7 \mathrm{~m}^{2}$ ); au sud, il était délimité par un mur monumental de $1,2 \mathrm{~m}$ de hauteur et de $15 \mathrm{~m}$ de long.

L'exploration s'est poursuivie sur les secteurs adjacents en 2006-2007 avec la partie occidentale du complexe ${ }^{33}$ (fig. 7). Plusieurs locaux de dimensions réduites et liés entre eux y ont été mis au jour. Une vaste cour d'une surface de près de $200 \mathrm{~m}^{2}$ et entièrement couverte de couches de chaux les jouxtait à l'ouest. On peut penser que la chaux avait servi de mortier appliqué à deux ou trois reprises sur un sol de terre battue. La cour était délimitée au nord, à l'ouest et au sud par la maçonnerie des bâtiments/locaux.

29. A. K. Korovina, Germonassa, p. 51-64.

30. Ibid., p. 59-61, ill. 29.

31. Ibid., p. 59.

32. Ibid., p. 51 sq.

33. S. I. Finogenova, T. A. Il’ina, V. N. Čkhaidze, «Novejšie rezul'taty issledovanij na Tamanskom gorodišče i nekropole», p. 249. 
Fig. 6 - Plan d'une résidence urbaine des IVe-III e s. av. J.-C., partie est. Fouille Nord. Dessin de Marija et Dar'ja Seliverstova.

Les vertus désinfectantes de la chaux étaient connues dès l'Antiquité, mais il est douteux que de tels sols aient été en usage dans les maisons d'habitation. Il est plutôt probable qu'on en recouvrait les enclos où l'on parquait le bétail en hiver et les cours des habitations. Au centre de la petite place, il y avait un foyer ouvert, sur une base d'argile battue. Près de lui ont été découvertes deux fosses, l'une remplie de feuilles de vigne, l'autre contenant des traces de fumier. Ces structures laissent penser que le secteur en question servait à des fins domestiques.

À en juger par les fragments d'amphores qui en proviennent, l'apparition du complexe doit remonter à la première moitié du IV $\mathrm{I}^{\mathrm{e}} \mathrm{s}$. av. J.-C. De nouvelles constructions annexes ont été ajoutées au nord et au sud au début du III s. av. J.-C. Dans l'une d'elles a été découvert en 1980 un petit autel de forme rectangulaire, fait de pierres en calcaire et couvert 
Fig. 7 - Résidence urbaine des IVe-III' s. av. J.-C., partie ouest. Fouille Nord, vue du sud. Photographie de Andrej Kudrjavickij et Sergej Ševčenko.

de tuile ${ }^{34}$. À l'intérieur, dans une couche de cendres, se trouvaient des os calcinés d'oiseaux et de petit bétail à cornes. C'est à ce même endroit qu'a été découvert un brûle-parfum en forme de demi-figure de Déméter avec un encensoir en forme d'entonnoir sur la tête.

En 2005, on a découvert dans ce même secteur les vestiges d'un complexe vinicole du III ${ }^{\mathrm{e}}$ s. av. J.-C. ${ }^{35}$. C'est apparemment dans cette partie ouest de la cité que se concentrait l'activité économique.

Il faut souligner que tous les bâtiments dans les secteurs ouest étaient orientés selon les points cardinaux ${ }^{36}$. Cela est peut-être à mettre en lien avec les périodes ultérieures de la construction de ce quartier.

34. S. I. Finogenova, "Germonassa», p. 518.

35. S. I. Finogenova, T. A. Il'ina, V. N. Čkhaidze, «Novejšie rezul'taty issledovanij na Tamanskom gorodišče i nekropole», p. 250.

36. S. I. Finogenova, "Germonassa», p. 518. 


\section{Religion et cultes de l'antique Hermonassa}

On peut supposer qu'à cette même époque les monuments architecturaux à caractère public et privé coexistaient avec des sanctuaires et des temples. C'est ce qu'indiquent des témoignages épigraphiques consacrés aux dieux de l'Olympe (CIRB 1041). Il est vraisemblablement fait écho ici au culte d'Aphrodite Apatouron (la trompeuse) sur deux morceaux d'un relief en marbre découverts près de Taman ${ }^{37}$ (fig. 8.1-2), où étaient représentées des figures de géants aux jambes en forme de serpents, conduits par Aphrodite dans la caverne où les attend Héraclès. Le relief a été perdu durant la Seconde Guerre mondiale. On en a conservé une photographie et la reconstitution qu'en avait faite Lev Petrovič Kharko. Selon son hypothèse, le relief avait appartenu à un temple (ou un trésor) ionien qui ne devait pas dépasser les cinq mètres. On a également retrouvé dans la cité un petit autel de calcaire du $\mathrm{IV}^{\mathrm{e}} \mathrm{s}$. av. J.-C., où devait vraisemblablement être installée la statue d'une déesse (fig. 8.3). Sur l'un des côtés a été gravée une dédicace: «Héraclide l'Héracléote, [pour] Aphrodite» ${ }^{38}$.

Quatre inscriptions consacrées à Apollon Iètros et Delphien ont été retrouvées dans les environs de Taman (CIRB 1044) (fig. 8.7). Une unique dédicace à Artémis d'Éphèse est gravée sur le pied d'un fauteuil de temple en marbre (CIRB 1040). Le texte est écrit au nom de la prêtresse en charge du culte de la déesse. De nombreux graffiti portant en monogramme les lettres initiales du nom de Déméter montrent que la popularité de cette déesse était grande parmi les habitants de la ville (fig. 8.4-6).

Parmi les monuments sculptés, citons un relief représentant Héraclès debout $^{39}$ (fig. 9), le bras droit appuyé sur son gourdin et sa peau de lion jetée sur le bras gauche. On doit à un maître du Bosphore une petite statue de femme dont seul le torse nous est parvenu ${ }^{40}$. En ce qui concerne le patrimoine décoratif, il faut signaler une plaque travaillée en relief figurant un ornement végétal, avec au centre une fleur d'aracée à boutons à

37. L. P. Kharko, «Fragment friza s izobraženiem gigantov iz stanicy Tamanskoj».

38. S. R. Tokhtas'ev, S. I. Finogenova, «Novye dannye o kul'te Afrodity v Germonasse», p. 86 sq.

39. L. I. Akimova (otv. red.), Antičnaja skul'ptura iz sobranija Gosudarstvennogo muzeja izobrazitel'nykh iskusstv im. A. S. Puškina, p. 52, no 17.

40. I. B. Zeest, «Raskopki Germonassy», p. 61. 
Fig. 8 - Objets épigraphiques et monumentaux à caractère sacré. Photographies de Andrej Kudrjavickij et Sergej Ševčenko. 


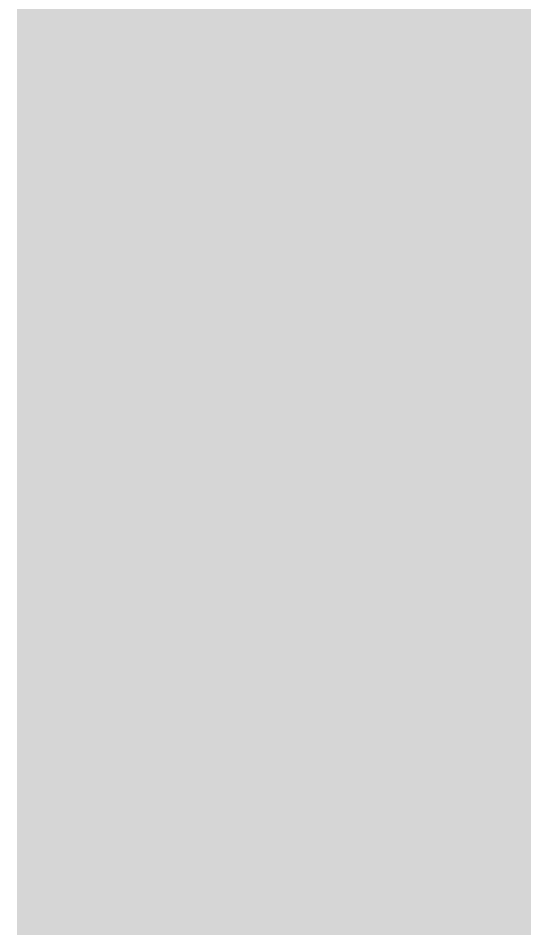

Fig. 9 - Relief avec représentation d'Héraclès. III ${ }^{\mathrm{e}}$ s. av. J.-C. Photographie de Andrej Kudrjavickij et Sergej Ševčenko. demi éclos et des feuilles d'acanthe aux rejets finement enroulés ${ }^{41}$. À en juger d'après une petite corniche ornant sa partie supérieure, la plaque faisait partie de la frise ornementale d'un bâtiment.

Le matériel amphorique, les pièces à figures noires et la céramique peinte indiquent qu'Hermonassa est devenue un centre économique développé aux $\mathrm{IV}^{\mathrm{e}}$-III e s. av. J.-C. Un commerce actif la lie avec les villes de la Grèce continentale et insulaire, d'Asie Mineure et du littoral sud de la mer Noire.

Plus de quatre siècles après la fondation de la ville, la majorité de la population restait encore grecque. C'est ce dont témoigne une liste de citoyens ioniens comportant quarante noms gravés dans une dalle de pierre (CIRB 1056).

\section{Hermonassa durant la période hellénistique tardive et la période romaine}

La vie économique d'Hermonassa commence à décliner à partir de la fin du III ${ }^{\mathrm{e}}$ s. av. J.-C. Aux II ${ }^{\mathrm{e}} \mathrm{I}^{\mathrm{er}}$ s. av. J.-C., l'épaisseur de la couche d'occupation n'atteint que $60 \mathrm{~cm}^{42}$. Les complexes monumentaux des époques précédentes sont détruits, certains détails architecturaux étant réutilisés dans des constructions ultérieures. Sur la fouille Nord, l'endroit de la résidence décrite plus haut est occupé au I ${ }^{\text {er }}$ s. av. J.-C. par des fours

4I. S. I. Finogenova, "Očerki istorii Germonassy po materialam raskopok poslednikh let», p. 429, ill. 6.2 .

42. I. B. Zeest, «Vozniknovenie i pervyj rascvet Germonassy», p. 85. 
de potiers que l'on installait de manière générale à l'écart des quartiers d'habitation. L'apparition d'une nécropole à $100 \mathrm{~m}$ de lieux occupés auparavant par des édifices publics permet de juger des frontières de la cité au tournant de l'ère chrétienne. Les trouvailles de cette couche relèvent de l'ordinaire, exemptes de céramique peinte ou d'importation. Les nombreux fragments d'amphores de Cnide et de Chios témoignent toutefois du maintien des contacts commerciaux déjà établis.

La ville commence à se rétablir à la fin du $\mathrm{I}^{\mathrm{er}} \mathrm{s}$. av. J.-C. La période entre la seconde moitié du I ${ }^{\mathrm{er}}$ av. J.-C. et le $\mathrm{II}^{\mathrm{e}}$ s. apr. J.-C. peut être considérée comme le second âge d'or d'Hermonassa ${ }^{43}$. L'épaisseur de cette couche d'occupation atteint $1,7 \mathrm{~m}$ et abonde en fragments architecturaux, ce qui témoigne d'une grande activité dans le domaine de la construction. Une inscription sur un socle de marbre datée de 105 apr. J.-C. évoque la reconstruction des portiques qui entouraient le temple d'Aphrodite Apatouron (CIRB 1045).

La comparaison entre les constructions des différents secteurs de la ville à cette époque révèle la règle générale suivante: les constructions sont de nature privée dans la partie nord-est et ont une fonction publique dans la partie centrale.

Il a été mis au jour en 1996 une grande maison (d'une surface de $30 \mathrm{~m}^{2}$ ) sur socle de pierre et aux murs de brique crue ${ }^{44}$. Les murs intérieurs de la pièce étaient enduits et décorés dans le style à incrustations caractéristique de l'architecture bosporane ${ }^{45}$. Une large gamme de couleurs y était utilisée, comprenant du rouge, du blanc, du rose, du lilas, du noir, du gris argent. Un registre du décor imitait un marbre sombre à veines colorées. Le sol de l'intérieur de la pièce était fait d'un gravier de calcaire d'une grosseur allant jusqu'à $3 \mathrm{~cm}$. Une cour domestique d'une surface d'environ $80 \mathrm{~m}^{2}$, couverte elle aussi d'un gravier de pierre, jouxtait la maison à l'ouest. Une rigole débouchant sur un petit bac pour la collecte de l'eau y a été conservée. À proximité, on a trouvé deux pithoi enterrés. La maison a été détruite dans un tremblement de terre: l'enduit a glissé des murs jusqu’au sol.

43. V. F. Gajdukevič, Bosporskoe carstvo, p. 320 et 336.

44. S. I. Finogenova, "Sistema rospisi pomeščenija I v. do n. è. v Germonasse», p. $13-20$.

45. M. I. Rostovcev, Antičnaja dekorativnaja živopis' na juge Rossii, p. 119, tab. XXXVII-XL; V. D. Blavatskij, "Fanagorijskaja rospis'»; S. I. Finogenova, «Nastennye rospisi i mozaičnye poly pantikapejskogo pritaneja». 
Fig. 10 - Lettre sur lamelle de plomb. I Ier siècle. Photographie de Andrej Kudrjavickij et Sergej Ševčenko.

La vie reprend dans ce secteur au cours du $\mathrm{I}^{\text {er }}$ siècle. Une nouvelle maison de trois pièces est érigée avec devant elle un pavage de dalles plates ${ }^{46}$.

En 2003, lors du démontage d'une maçonnerie du I ${ }^{\text {er }}$ siècle sur la fouille Nord-Est, on a découvert une lamelle de plomb pliée trois fois ${ }^{47}$ (fig. 10). Sur sa face externe ont été gravées à la fine pointe douze lignes d'un texte en grec. L'état de conservation ne permet pas de lire le texte en entier. On a pu établir qu'il était destiné à être envoyé à Nymphaion, ce qui pour une raison inconnue n’a pas été réalisé. Le matériau céramique des $\mathrm{II}^{\mathrm{e}}$-III $\mathrm{I}^{\mathrm{e}}$ siècles est abondant, mais uniforme. Il y prédomine des fragments de bols à vernis rouge et de vaisselle d'usage quotidien. La vaisselle d'apparat est représentée par des plats ovales à anses en relief. L'un d'eux présente en son centre une figure de sphinx estampée dans un rectangle (fig. 11).

Aux II ${ }^{\mathrm{e}}-\mathrm{III} \mathrm{e}^{\mathrm{e}}$ siècles surviennent des signes de changements dans la sphère religieuse. Dans de nombreux thiases du Bosphore, à côté de la

46. S. I. Finogenova, "Germonassa», p. 521.

47. S. I. Finogenova, "Očerki istorii Germonassy po materialam raskopok poslednikh let», p. 428, ill. 3.1 . 
Fig. 11 - Plat à vernis rouge avec représentation d'un sphinx assis. III ${ }^{\mathrm{e}}$ siècle. Photographie de Andrej Kudrjavickij et Sergej Ševčenko.

Fig. 12 - Objets épigraphiques et monumentaux de l'Antiquité tardive et du MoyenÂge. Photographies de Andrej Kudrjavickij et Sergej Ševčenko, dessins de Marija et Dar'ja Seliverstova. 
vénération des dieux du panthéon grec apparaît celle du «dieu suprême, tout-puissant»(CIRB 1286) (fig. 12.1). On a des mentions de la construction d'une maison de prière. Au début du IV ${ }^{\mathrm{e}}$ siècle, le christianisme connaît une large diffusion dans le Bosphore ${ }^{48}$. Une quantité importante de céramique à vernis rouge présente des estampes avec croix ou poisson (fig. 12.2). En 1868, on a retrouvé à Taman une colonne de marbre portant une inscription et des croix peintes.

\section{Invasions des Goths: résultats et conséquences}

L'histoire de la ville antique d'Hermonassa prend fin avec l'arrivée des peuples nomades. C'est au milieu du III e siècle que le Bosphore subit les incursions des Goths. Le matériel archéologique témoigne de l'appauvrissement des habitants: il n'y a pas d'édifices monumentaux, les appareils de pierre se sont mal conservés, le pourcentage de céramique d'importation est négligeable, l'épaisseur de la couche d'occupation ne dépasse pas le mètre.

En 2016, des éléments de la seconde moitié du III siècle ont été explorés sur la fouille Nord ${ }^{49}$. Pour autant qu'on puisse en juger par les vestiges de constructions très fragmentaires, les maisons étaient assez précisément disposées selon un agencement presque quadrangulaire et étaient regroupées en quartiers (fig. 13).

Les bâtiments découverts ne relèvent d'aucun ordre architectural et ont une surface comprise entre 38 et $45 \mathrm{~m}^{2}$. Ils comportaient une ou plusieurs pièces couvertes donnant sur une cour pavée.

Les traces d'activité qu'on y a découvertes (des fosses à grain, des amphores avec du sable de quartz, des auvents avec plate-forme de pierre) laissent penser qu'il s'agissait de complexes d'habitation et d'exploitation. Cinq de ces complexes ont été découverts au total.

Durant l'Antiquité tardive, l'orientation des constructions change lorsque les intérêts économiques des habitants se trouvent dans une grande mesure orientés vers les territoires agricoles, qui s'étendent

48. È. Ja. Nikolaeva, «Krasnolakovaja keramika so štampami s Il’ičevskogo gorodišča", p. 113.

49. T. A. Il'ina, Otčjot o raskopkakh na territorii gorodišča Germonassa-Tmutarakan' 2016 g., p. 17. 
Fig. 13 - Complexes d'habitation et d'exploitation de la première moitié du III e siècle. Fouille Nord, vue du sud. Photographie de Andrej Kudrjavickij et Sergej Ševčenko.

surtout dans les régions des steppes, au sud de la ville. Les complexes sont séparés de rues d'une largeur pouvant atteindre $1,2 \mathrm{~m}$ et présentant des vestiges de rigoles.

Les fondations des maisons sont traditionnellement en pierre, alors que les murs sont faits de brique crue. La largeur des murs est de $50 \mathrm{~cm}$ et atteint $65 \mathrm{~cm}$ à la base. Les appareils découverts, à double parement et remplissage de blocaille de calcaire fin et moyen, ont été conservés sur une ou deux rangées, lorsqu'ils n'ont pas été démontés. À en juger par la différence de niveau où reposent les extrémités opposées des appareils, on ne procédait pas sur les chantiers à de minutieux travaux d'égalisation et de nivellement. Au-dessus des maçonneries, on a déblayé des restes de murs de brique crue écroulés. Dans certains cas, les fondations étaient faites de pierres déposées de manière irrégulière et non ajustée, les espaces vides étant remplis d'argile.

On a pu relever à quelques endroits l'entaille soignée d'une ancienne ouverture de porte ou d'un bord de fenêtre. À en juger par la configuration des seuils de pierre, les maisons avaient un dispositif assez développé 
de jambages et de pans de portes sur charnières. L'exploration des secteurs formés suite à la chute de la couverture permet de dire que les toits étaient à un pan, couverts de joncs ou de roseaux.

Certains complexes ont pu connaître plusieurs périodes de construction.

Ainsi, en 1973, à la limite entre la fouille Nord et la fouille Haute, on a découvert un bâtiment monumental à pilastres comprenant plusieurs pièces ${ }^{50}$. Son appareil nord avait une longueur de 19,8 m. D'après A. K. Korovina, il avait été construit à la fin du II siècle et a été détruit par un incendie dans la seconde moitié du III e siècle. En 1970, durant le déblayage du pavage de la partie sud du complexe, on a découvert un petit pot avec 44 statères de billon de Rhescuporis V. Dans la publication de ce trésor, Vladimir Konstantinovič Golenko émet l'hypothèse qu'il a été enterré en 252, peu avant les invasions des Goths qui ont pu être à l'origine de l'incendie du bâtiment ${ }^{51}$.

Les traces des incendies présentes dans cet horizon de la fouille Haute ont été révélées sur toute la surface de la fouille Nord en 2016-2017 52. L'épaisseur de la couche incendiée atteint parfois $15-20 \mathrm{~cm}$. Les monnaies qui en proviennent datent de 262-263 et déterminent le terminus post quem de cette catastrophe.

Certaines trouvailles faites dans une fosse de déchets, mise au jour dans la cour intérieure de l'un de ces complexes d'habitation et d'exploitation ${ }^{53}$, sont peut-être elles aussi la conséquence d'une invasion ennemie. On a découvert à une profondeur de $50 \mathrm{~cm}$ de la surface du sol deux crânes d'hommes sur lesquels reposaient deux squelettes décapités. Au-dessus, à $10 \mathrm{~cm}$ du niveau de sol actuel, se trouvaient les crânes brisés d'un enfant et d'une femme. Le crâne juvénile appartenait à un enfant de 5-6 ans: une partie importante n'en a pas été conservée, la mâchoire supérieure est perdue, les dents ont été retrouvées dispersées. La femme avait environ 45-55 ans. On lui a diagnostiqué un édentement, mais aucune autre pathologie.

50. A. K. Korovina, Germonassa, p. 73 sq.

5I. T. N. Knipovič, «Krasnolakovaja keramika pervykh vekov našej èry iz raskopok Bosporskoj èkspedicii 1935-1940 gg.", p. 306, ill. 6-7.

52. S. I. Finogenova, Otčjot o raskopkakh na territorii gorodičča GermonassaTmutarakan' 2017 g., p. 12.

53. T. A. Il'ina, Otčjot o raskopkakh na territorii gorodišča Germonassa-Tmutarakan' 2016 g., p. 29. 
Le squelette appartenait à un homme de 45-50 ans. Les bras, les clavicules, les pieds ont été perdus. Le crâne, retrouvé sous la hanche, a été conservé avec trois vertèbres jointes, ce qui indique qu'il a été déposé avec les tissus mous. On n'a pas retrouvé de traces de sectionnement. Le sternum et le sacrum étaient disposés selon leur ordre anatomique. La jambe droite était pliée vers l'arrière dans une position non naturelle. Le fémur gauche est conservé, la rotule disposée au-dessus. Les épiphyses inférieures des fémurs portent des traces de dépeçage; il est possible que les jambes aient été tranchées pour permettre un enfouissement plus aisé dans une fosse peu profonde. Sur le crâne, on a relevé les traces de deux blessures pénétrantes cicatrisées.

Tout contre lui, il y avait le crâne d'un homme de 45-55 ans. À la surface des deux crânes, on a relevé des enfoncements à l'endroit où ils étaient en contact.

À en juger par leur état de conservation, ces restes humains d'enfants et de vieillards ont été inhumés dans une fosse domestique, alors qu'ils étaient morts depuis bien longtemps. Cela s'est peut-être fait dans un but sanitaire, alors que la vie reprenait dans la cité.

Le matériel céramique de la période de construction qui s'ouvre comporte des amphores d'argile rouge de la seconde moitié du III e siècle, des tasses à vernis rouge, des bols, de la vaisselle d'argile rouge et modelée, des plombs de pêche pyramidaux et des fusaïoles biconiques ${ }^{54}$.

Une trouvaille très intéressante est celle d'un moule de plâtre pour l'empreinte de plaquettes avec la tête de la Gorgone Méduse, destinées à décorer des sarcophages de bois (fig. 14.11). D’autres objets de verre et de bronze ont été trouvés là: des fibules, petites perles et perles-tubes, agrafes, pincettes (fig. 14.3, 6-7, 8-10, 12-13).

\section{À la veille de l'invasion des Huns}

La ville s'anime durant la première moitié du IV ${ }^{\mathrm{e}}$ siècle: sur la fondation du mur nord du "bâtiment à pilastres", sur la fouille Haute, on érige un nouveau complexe qui survit à l'invasion des Huns ${ }^{55}$. C'est à cette époque qu'est créé le décor architectural de sa façade nord, avec quatre

54. Ibid., p. 44 sq.

55. A. K. Korovina, Germonassa, p. 73 sq. 
Fig. 14 - Trouvailles des couches de l'Antiquité tardive. Photographies de Andrej Kudrjavickij et Sergej Ševčenko, dessins de Marija et Dar’ja Seliverstova. 
Fig. 15 - Horizon de construction de l'invasion gothe. Fouille Nord, vue du sudouest. Photographie de Andrej Kudrjavickij et Sergej Ševčenko.

saillies pour les colonnes ornant le mur extérieur. L’espace intérieur était délimité par une cloison parallèle au mur est de la maison. La moitié ouest était pavée de dalles plates.

Trois lignes d'implantation urbaine ont été explorées au centre et dans la partie nord de la fouille Nord (fig. 15). Entre elles, on a pu révéler des zones de pavage qui conduisaient jusqu'aux ouvertures des portes. Le bâtiment central comportait trois pièces et ses murs étaient à double parement, avec remplissage de calcaire fin et moyen. Des restes de murs de brique crue ont été identifiés au-dessus des appareils et des morceaux du sol et du plafond effondré ont été retrouvés à l'intérieur du bâtiment. Le prosaïsme des bâtiments découverts s'explique tant par leur mauvais état de conservation, dû au prélèvement ultérieur sauvage de pierres, que par la pauvreté des couches anthropiques elles-mêmes, ce qui à son tour témoigne de l'affaiblissement économique de la ville.

Découverts à cet endroit, des statères de Rhescuporis VI et de Thothorsès, dont le plus récent est daté de 329, servent de terminus post quem à l'apparition de ce nouvel horizon. 
La plus grande partie du matériel céramique est représentée par de la production d'ateliers du Bosphore et du Pont ${ }^{56}$. Il s'agit avant tout de fragments d'amphores d'argile rouge de l'époque romaine tardive et de vaisselle à vernis rouge: des bols à bord haut, des tasses et des assiettes de céramique sigillée pontique parfois à décor estampé.

De là provient une quantité importante de lampes à bec arrondi et à profil biconvexe, ainsi que des lampes de forme allongée avec un trou de remplissage surélevé (fig. 19.24-26). On y a en outre trouvé des encensoirs, aussi bien grossièrement moulés que tournés.

Au rang des trouvailles uniques, il y a des objets de l'artisanat romain: une applique en os de seconde utilisation avec une représentation d'Éros conduisant un char; une attache d'anse de vase en bronze en forme de buste d'homme barbu; une grande perle sphérique en pâte de verre multicolore avec pendentif (fig. 14.1-2, 4-5).

Quant aux objets en bronze, ils sont variés: fragments de bracelets, de fibules et d'anneaux temporaux, éléments d'assortiments pour ceintures, une bague à chaton plat, des pointes de flèche à trois lobes, des petits poids. La multitude de fusaïoles biconiques d'argile, les trouvailles de poids pour filets de pêche, les supports à aiguiser en os et les meules témoignent de la vigueur de l'artisanat et de la petite industrie.

\section{Ateliers vinicoles de l'Antiquité tardive}

Trois complexes de viniculture sont construits dans la ville à cette époque. Le plus important a été découvert en 1981 par A. K. Korovina sur la fouille Haute; son exploration s'est poursuivie en 2013-2014 ${ }^{57}$ (fig. 16). La partie occidentale conservée est typique des exploitations vinicoles du Bosphore, avec cinq plates-formes de pressurage (deux latérales, deux centrales et une inférieure) et trois cuves ${ }^{58}$. Une plateforme centrale avait une dalle quadrangulaire pour le pressage du raisin à l'aide d'un pressoir à levier avec vis.

Jouxtant à l'est la plate-forme nord, une plate-forme secondaire servait au transvasement du moût des cuves. À en juger par les morceaux de

56. Ibid., p. 56.

57. A. K. Korovina, "Vinodel'ni Germonassy», p. 60 sq.

58. V. F. Gajdukevič, «Vinodelie na Bospore», p. 409. 
Fig. 16 - Complexe vinicole des IVe-Ve siècles. Fouille Haute, vue de l'ouest. Photographie de Andrej Kudrjavickij et Sergej Ševčenko.

maçonnerie de blocage conservés, une plate-forme similaire était située au sud. Les plates-formes étaient recouvertes d'une maçonnerie de blocage dont l'épaisseur pouvait attendre 8-9 couches. On a retrouvé des traces d'hématite qui servait à préserver la surface de la corrosion par le moût de raisin. Entre les plates-formes de pressurage ont été conservées les entailles dans lesquelles s'inséraient des planches de séparation. De telles entailles ont également été relevées entre deux plates-formes centrales, où dans les angles se trouvaient aussi des orifices verticaux, peutêtre des rigoles pour l'évacuation du moût.

À l'est des plates-formes se trouvaient des cuves. Pour leur construction, on avait creusé une fosse dont les parois ont été habillées de pierres, après quoi des cloisons en pierre ont été construites. Les parois ont ensuite été habillées d'une maçonnerie de blocage et enduites d'hématite. Des cavités de décantation ont été faites dans la moitié est de chaque cuve pour le transvasement des restes de moût. Au total, le volume des trois cuves s'élevait à plus de 4’000 litres.

Par analogie avec les exploitations vinicoles de Tiritaka, on peut supposer qu'entre les plates-formes de pressurage et les cuves, il y avait des murets de faible hauteur pour que le raisin ne tombe pas dans les cuves lorsqu'on le pressurait. À l'angle nord-est de la plate-forme sud, on a découvert, scellé dans le sol maçonné, un col d'amphore qui servait à l'évacuation. En 1986, à l'est de la cuve, un espace en sous-sol a été découvert avec un pithos enterré, probablement un chai. 
Tirant un parallèle avec les ateliers vinicoles du littoral nord de la mer Noire, A. K. Korovina date celui découvert en 1981 des II $^{\mathrm{e}}-\mathrm{III}^{\mathrm{e}}$ siècles ${ }^{59}$. L'examen des trouvailles issues des cuves et des plates-formes de pressurage révéla leur hétérogénéité. Il s'agit aussi bien de fragments d'amphores en argile rouge des $\mathrm{II}^{\mathrm{e}}-\mathrm{III} \mathrm{e}^{\mathrm{e}}$ siècles que de bris de vases à vernis rouge estampés des $\mathrm{V}^{\mathrm{e}}-\mathrm{VI}^{\mathrm{e}}$ siècles et de hautes cruches à anses plates du Moyen-Âge. À en juger par les nombreux retournements de couches pratiqués par la suite et dont les rapports font part, ainsi que par les fosses khazars, le complexe de vinification détruit n'était pas couvert et a probablement servi de dépotoir. Si l'on tient compte de cela, il semble plus vraisemblable de dater l'existence du complexe par le matériel de la couche adjacente, soit pas avant 329.

Il faut signaler qu'un atelier vinicole analogue, mis au jour par Svetlana Finogenova en 1983 dans la partie ouest de la fouille Nord, se situe lui aussi dans l'horizon de construction du $\mathrm{IV}^{\mathrm{e}}$ siècle $^{60}$.

Le développement de la viniculture s'accompagne d'une intensification de la production de céramique de stockage. Les trouvailles de fours de cuisson ne sont pas nombreuses. Un four circulaire à parois de pierre habillées de brique crue, avec colonne de soutènement centrale, a été mis au jour sur la fouille Haute en 1952. Sa couverture était garnie de briques en forme de biseau. Cette technique, qui n'est pas caractéristique des Grecs, est empruntée aux tribus locales de la région du Kouban.

Le commerce régulier mené avec les tribus du Caucase Nord a permis leur pénétration dans la région. Certains ressortissants de tribus nomades alanes et sarmates se sédentarisent dans les villes du Bosphore. On a retrouvé à Hermonassa une inscription dédicatoire attestant qu'il existait dans la ville une cellule de traducteurs alains dirigée par un certain Hèrakas fils de Pontikos (CIRB 1053) (fig. 17.1).

L'élevage de bovins est l'activité principale des habitants de Taman durant cette période. Les trouvailles de houes, de meules et de fosses pour le stockage du grain attestent de l'existence d'une activité agricole et de minoterie.

Durant la seconde moitié du IV ${ }^{\mathrm{e}}$ siècle, les hordes de Huns traversant les steppes de la région de la mer Noire causent la ruine de presque toutes les villes grecques du littoral nord. La situation d'Hermonassa, à

59. A. K. Korovina, «Vinodel'ni Germonassy», p. 60 sq.

6o. Ibid. 
Fig. 17 - Objets épigraphiques et monumentaux de l'Antiquité tardive et du MoyenÂge. Photographies de Andrej Kudrjavickij et Sergej Ševčenko.

l'écart de la route principale des nomades et du lieu où ils franchissent le détroit, permit la préservation de la ville. On n’a relevé aucune trace d'incendie ou de destruction catastrophique. La construction d'ateliers vinicoles sur le lieu d'anciens bâtiments monumentaux montre l'intensification du processus de désurbanisation et le changement d'aspect progressif de la ville antique.

Les sources évoquant la vie de la ville après l'invasion sont insignifiantes. A-t-elle conservé son nom? Était-ce une ville ou une simple implantation? Il n'y a pas de témoignage d'un abandon total d'Hermonassa. La trouvaille d'une borne de domaine halieutique confirme l'existence d'un certain ordre administratif.

La céramique de cette période provient principalement de la production des ateliers du Bosphore. Les ustensiles de ménage sont dominés par de la vaisselle moulée, avec divers pots, terrines, vases et bols. De nombreux chercheurs observent que la diffusion à grande échelle de ce type de céramique dans l'Antiquité tardive est non seulement un indice de pauvreté et de retour à une économie de subsistance, mais aussi le témoin d'un changement dans la composition ethnique de la population dû à un large afflux de tribus non grecques. 


\section{Période byzantine de la cité de Taman}

L'influence de Byzance commence à atteindre Hermonassa aux $\mathrm{V}^{\mathrm{e}}$ et $\mathrm{VI}^{\mathrm{e}}$ siècles, avec l'apparition de monuments liés à la culture byzantine: deux chapiteaux de colonne et une dalle à relief avec la représentation d'un ange ${ }^{61}$ (fig. 17.2).

En 2013, on a déblayé dans la partie nord de la fouille Nord la fondation d'un four rectangulaire à deux chambres avec rangée inférieure en brique crue et sole au nord ${ }^{62}$. Aucun résidu de production n'a été retrouvé, mais à en juger par les dimensions du four, il était utilisé pour de l'artisanat.

Au centre de la zone explorée, on a mis au jour des portions de maçonnerie en file ou parallèles selon une orientation ouest-est et ne formant aucune construction complète (fig. 18). Au nord de celles-ci a été découverte une portion de pavage et de rigole, fait de pierres plates dressées en orthostates et couvertes par les fragments d'une architrave.

Dans la partie sud de la zone découverte, à la frontière avec la fouille Haute, on a mis au jour les vestiges d'une pièce et les ruines de deux petits fours. Au cours du déblayage de cendres évacuées sur l'escarpement nord de la fouille, on a retrouvé deux squelettes de chien en ordre anatomique.

Deux monticules de cendres ont également été identifiés près de la limite ouest de la zone explorée. Le premier était le rejet d'un grand four de poterie du IX siècle, étudié en 2005 à cet endroit deux couches plus haut; le deuxième, un dépôt de coquilles de moules.

Compte tenu de la grande quantité de fragments d'amphores de la période romaine tardive (notamment de production cilicienne), ainsi que de trouvailles de tasses à vernis rouge et d'assiettes à ornement estampé en forme de croix, de poissons ou de fleurs, ainsi que de plats de production sigillée africaine, la couche doit être datée du $\mathrm{V}^{\mathrm{e}}$ siècle au troisième quart du VI siècle.

Malheureusement, les monnaies de bronze découvertes à cet endroit (plus de cent exemplaires) ont une grande période de circulation et ne

6I. A. K. Korovina, Germonassa, p. 51-64, 93 sq., ill. 48-49.

62. T. A. Il'ina, "Rezul'taty issledovanij Tamanskogo gorodišča (po materialam 2005-2015 gg.)», p. 53. 
Fig. 18 - Plan de quartier urbain VIII'-IX siècles. Dessin de Marija et Dar'ja Seliverstova.

sont pas informatives pour la datation (les statères bosporans frappés par Rhescuporis VI et Thothorsès sont longtemps restés en circulation).

Des objets de bronze ou de plomb sont typiques de cette période: amulettes, fibules, bracelets, détails d'assortiments de ceinture, pointes de flèches à trois lobes, clés, pendentifs et poids (fig. 19.12, 14-18).

Parmi les objets en os, citons des peignes, fermoirs et outils (alênes, lissoirs), ainsi que de petits objets manufacturés comme une ébauche de petite flûte et un pendentif (fig. 19.19, 21-23).

\section{La Tamatarkha médiévale}

L'histoire de la Tamatarkha au Moyen-Âge commence au dernier quart $\mathrm{du} \mathrm{VII}^{\mathrm{e}}$ siècle, lorsque la ville passe sous domination khazare ${ }^{63}$. La superficie de la ville de Tamatarkha a pu atteindre 30 ha. Par analogie avec Chersonèse, qui était de taille similaire, la population de la ville

63. V. N. Čkhaidze, Tamatarkha, p. 298. 
Fig. 19 - Trouvailles des couches médiévales. Photographies de Andrej Kudrjavickij et Sergej Ševčenko. 
pouvait se monter à environ 6’000 habitants. La ville abritait des descendants des populations bosporanes locales, la population «civile» du khaganat - Bulgares et Khazars, ainsi que des Alains, Byzantins, Juifs et nomades. Grâce sa situation isolée, la ville ne subit pas de grandes invasions de l'extérieur.

Les tribus nomades apportent des types nouveaux de céramique et des techniques renouvelées d'inhumation et de construction. On a identifié deux types de maisons d'habitation, les vestiges d'un bâtiment-donjon hexagonal, des fortifications et une urbanisation caractéristique des villes du Moyen-Âge du littoral nord de la mer Noire.

Les couches de cette période ont été explorées en 2011-2012 ${ }^{64}$. Une portion d'un bâtiment de plus de $10 \mathrm{~m}^{2}$, dont la moitié est se trouve au-delà de la fouille, a ainsi été fouillée dans la partie nord de la fouille Nord. Un four a été construit contre son mur ouest; la partie est a été traversée par un énorme dépôt de déchets au IX ${ }^{\mathrm{e}}$ siècle.

Dans la partie sud de la fouille, des éléments de construction ne formant aucun édifice complet ont été déblayés, avec éléments de sols en terre battue et débris de céramique. Il est possible que ces constructions soient à mettre en lien avec les restes d'un grand four de potier du VIII siècle disposé au centre de la zone. Au nord-est de ce dernier, on a trouvé douze "statères" en bronze de Thothorsès (298-308) et de Rhescuporis VI (318-332) qui ont eu une longue période de circulation.

Sur toute la zone explorée, on a découvert quarante fosses domestiques avec des restes de tourteaux de raisin, des grains, des écailles de poisson et des fragments d'amphores et de cruches de stockage.

Au cours du déblayage d'une fosse à déchets située au centre de la fouille Nord, au fond, dans une couche de limon brun chargé de cendres, de brique crue, d'arêtes de poissons et d'os d'animaux, on a découvert l'inhumation d'une femme de 30-35 ans, reposant sans trousseau funéraire, recroquevillée sur le flanc droit et dans le sens ouest-est ${ }^{65}$. L'étude du squelette a révélé la présence de tartre, une hypoplasie de l'émail, une pathologie maxillo-dentaire, des caries, une spondylose et de l'arthrose.

Une autre inhumation de femme a été mise au jour dans la partie centrale de la fouille Nord, dans une couche dense de limon jaune. Le

64. T. A. Il'ina, «Rezul'taty issledovanij Tamanskogo gorodišča (po materialam 2005-2015 gg.)», p. 52.

65. Ibid. 
haut du torse était surmonté d'une bûche qui avait été passée au feu et dont les veines étaient encore distinctes. Le squelette reposait dans une position à demi recroquevillée, sur le flanc droit, les bras contre la poitrine, les genoux pliés, dans une orientation ouest-est, le visage tourné vers le sud. Il n’a pas été relevé de mobilier funéraire, mais on a retrouvé près de l'inhumation une perle-tube décorée d'une croix, de production byzantine. À en juger par le crâne, la conservation des dents et les os de la hanche, la défunte avait environ 35-45 ans. On a observé du tartre, une pathologie maxillo-dentaire, la perte de son vivant des troisièmes molaires supérieures droites et gauches, une spondylose, une spondylose déformante des lombaires et de l'arthrose.

Aucun mobilier n'a été relevé, mais près de la tombe, on a retrouvé un séparateur de chaîne en or décoré d'une croix byzantine en argent, production du VIe siècle (fig. 19.7).

La partie supérieure de l'inhumation a été nivelée avec une couche de brique crue au-dessus de laquelle on a construit un bâtiment qui a connu trois périodes d'existence avant d'être détruit dans un incendie au VII ${ }^{\mathrm{e}}$ siècle.

Citons parmi les objets retrouvés à cet endroit une estampille sur anse d'amphore, une embouchure d'outre en os avec bouchon, un pendentif en bronze en forme d'idole de la fertilité, un anneau sigillaire nominatif avec une étoile gravée ${ }^{66}$ (fig. 19.5-6, 13, 20). L’essentiel du matériel est composé de fragments d'assiettes à vernis rouge avec ornement estampé du VI ${ }^{\mathrm{e}}$ siècle.

Les nombreuses trouvailles d'objets du quotidien laissent penser que le filage, le tissage et la sculpture sur os étaient développés dans la ville. De grands fours à céramique et de verrerie ont été découverts à la périphérie de la ville. Il n'y a pratiquement aucun indice de présence de l'artisanat du fer ou du travail des métaux.

Au cours des travaux de 2009-2010, il a été mis au jour des structures archéologiques relevant de trois couches de construction de la seconde moitié du IX $\mathrm{X}^{\mathrm{e}}$ siècle et du début du $\mathrm{X}^{\mathrm{e}}$ siècle ${ }^{67}$. Les vestiges de trois bâtiments ont été explorés à la limite entre les fouilles Haute et Nord et on a relevé plusieurs niveaux de sols de terre battue marqués par des débris

66. Ibid., p. 54 .

67. S. I. Finogenova, T. A. Il'ina, V. N. Čkhaidze, «Novejšie rezul'taty issledovanij na Tamanskom gorodišče i nekropole», p. 250 sq. 
de céramique. On a également exploré deux grands fours, peut-être de poterie, ainsi que deux foyers.

Dans la couche en question, on a découvert plus de trente fosses de type fosse à déchets et une quantité importante de déchets de production d'un four. Le long de la limite nord de la fouille Nord, tout au bord, on a déblayé deux pithoi enterrés. Tous les vestiges de constructions de ce territoire ont été détruits; des traces d'incendie ont été identifiées.

Parmi les objets d'intérêt issus de cette couche, citons une gemme cornaline avec oiseau, un graffiti figurant un rameur, un pendentif en pièce de monnaie à l'apparence d'un dimhar omeyyade du VII ${ }^{\mathrm{e}}-\mathrm{VIII}{ }^{\mathrm{e}}$ siècle, une bague de bronze à chaton incrusté et une petite croix de type chersonésite incrustée de mica ${ }^{68}$ (fig. 19.2-4, 8-11).

En dépit des changements de son statut politique et idéologique, ainsi que des transformations de la composition ethnique de sa population, la ville reste un centre commercial important jusqu'à la fin du XVII siècle. La situation de Tamatarkha sur le littoral du détroit de Kertch a joué un rôle clé en tant que carrefour de routes commerciales fréquentées de l'Europe de l'est des VII ${ }^{\mathrm{e}}-\mathrm{X}^{\mathrm{e}}$ siècles.

Le commerce avec l'Empire byzantin, avec les voisins et avec les nomades a joué un rôle prépondérant dans l'économie de Tamatarkha. Il y avait dans la ville toute une corporation de collecteurs d'impôts, ce dont attestent les trouvailles de dizaines de sceaux des logothètes généraux, les représentants de l'administration financière de l'empire, et notamment de bulles de plomb de l'éparque Basile du $\mathrm{X}^{\mathrm{e}}$ siècle (fig. 19.1) ${ }^{69}$. Ils assuraient le contrôle fiscal sur les prélèvements des taxes d'importation et d'exportation, ainsi que ceux des impôts de l'État.

Un grand nombre de restes de fours de poterie et de vestiges d'activité de production ont ainsi été découverts au cours des travaux de 20052013 sur les secteurs nord-ouest de la fouille Nord et «Peremyčka». Cela permet de supposer l'existence dans cette partie de la ville d'un quartier d'artisans, apparu au tournant des $\mathrm{V}^{\mathrm{e}}$ et $\mathrm{VI}^{\mathrm{e}}$ siècles et qui a perduré jusqu'au IX ${ }^{\mathrm{e}}$ siècle.

Il est possible que Tamatarkha ait fait partie, avec Phanagorie, Bospor et les autres centres byzantinisés de Tauride, du système de "dyarchie"

68. Ibid., p. 252, ill. 8, 15, 23.

69. V. N. Čkhaidze, T. A. Il’ina, "Novye nakhodki vizantijskikh pečatej na territorii Tamanskogo gorodišča», p. 159. 
Fig. 20 - Tamatarkha aux $\mathrm{X}^{\mathrm{e}}-\mathrm{XI}^{\mathrm{e}}$ siècles. Fouille Nord, vue de l'est. Photographie de Andrej Kudrjavickij et Sergej Ševčenko.

byzantino-khazare ${ }^{70}$. Les représentants du pouvoir des deux puissances étaient simultanément présents dans la ville pour toucher divers revenus sous la forme d'impôts ou de tributs. Ce système de rapports réciproques s'est poursuivi jusqu'au deuxième tiers du IXe siècle.

Konstantin Bagrjanorodnyj qualifie Tamatarkha de kastron («forteresse») (fig. 20). Il est possible que l'apparition d'un mur de défense soit à mettre en lien avec les invasions des tribus magyares, puis petchénègues. Des chefs militaires khazars s'y trouvaient en temps de paix avec leur détachement régulier, et en temps de guerre, un contingent militaire allant jusqu'à 40 '000 hommes pouvait être levé ${ }^{71}$.

L'affaiblissement de l'empire khazar à la fin du IXe-début du Xe siècle conduit à une courte période d'intensification de l'influence de Byzance et l'apparition d'un évêque. Les fortes couches d'incendie mises au jour au cours des fouilles peuvent être associées à la prise de la ville par les troupes de Sviatoslav I ${ }^{\text {er }}$ en 965 ou de Vladimir I ${ }^{\text {er }}$ en 987-98972.

70. V. N. Čkhaidze, Tamatarkha, p. 296.

7I. M. I. Artamonov, Istorija Khazar, p. 431.

72. V. V. Majko, «Khazaro-russko-vizantijskie otnošenija v seredine X v. i Krymskaja Khazarija", p. 251 et Srednevekovoe gorodišče na plato Tepsen'v jugo-vostočnom Krymu, p. 44. 
Le déclin n'affecte pas longtemps la vie économique et culturelle de la ville. La production artisanale reprend avec une vigueur renouvelée, les importations se poursuivent, les quartiers détruits sont reconstruits. À en juger par les objets de la culture matérielle, il n'y a pas de changement cardinal dans la population. La ville change seulement de nom et devient Tmutarakan, avant-poste méridional de la Russie kiévienne. Au troisième quart du $\mathrm{XV}^{\mathrm{e}}$ siècle, la ville tombe sous domination turque.

Svetlana Il'inična Finogenova Musée des Beaux-Arts Pouchkine, Moscou

Tat' jana Anatol'evna IL'InA Musée des Beaux-Arts Pouchkine, Moscou Traduction du russe de Fabrice Guibentif 


\section{BIBLIOGRAPHIE}

Aкimova, Ljudmila Ivanovna (otv. red.), Antičnaja skul'ptura iz sobranija Gosudarstvennogo muzeja izobrazitel'nykh iskusstv im. A. S. Puškina [La sculpture antique dans la collection du musée des Beaux-Arts Pouchkine], Moskva, Izobrazitel'noe Iskusstvo, 1987.

Artamonov, Mikhail Illarionovič, Istorija Khazar [Histoire des Khazars], Leningrad, Izdatel'stvo Gosudarstvennogo Ėrmitaža, 1962.

Arzamanov, Grigorij Fjodorovič, "Arkhaičeskaja kapitel' iz Tamani» ["Un chapiteau antique de Taman»], Vestnik drevnej istorii, 4 (1989), p. 49-54.

Blavatskij, Vladimir Dmitrievič, «Arkhaičeskij Bospor» " Le Bosphore archaïque»], Materialy $i$ issledovanija po arkheologii SSSR, 33 (1954), p. 7-44.

—, "Fanagorijskaja rospis” " [Décoration peinte de Phanagorie»], Materialy $i$ issledovanija po arkheologii SSSR, 57 (1956), p. 168-170.

CIRB = STRUve, Vasilij Vasil'evič, et alii, Korpus bosporskikh nadpisej [Corpus des inscriptions bosporanes], Moskva/Leningrad, Nauka, 1965.

ČKHAIDze, Viktor Nikolaevič, Tamatarkha. Rannesrednevekovyj gorod na Tamanskom poluostrove [Tamatarkha. Une ville du Haut MoyenÂge de la péninsule de Taman], Moskva, Taus, 2008.

Č́nаıдze, Viktor Nikolaevič, IL'ina, Tat'jana Anatol'evna, "Novye nakhodki vizantijskikh pečatej na territorii Tamanskogo gorodišča» [«Nouvelles trouvailles de sceaux byzantins sur le territoire de la cité de Taman»], Vizantijskij vremennik [Chronique byzantine], Moskva, 2012, vol. 71, p. 159-166.

Dionisij Perièget / Per. V. V. Latyševa [Denys le Périégète / trad. de V. V. Latyšev], Zapiski Imperatorskogo Russkogo arkheologičeskogo obščestva [Mémoires de la Société impériale russe d'archéologie], Sankt-Petersburg, 1892, t. 6, nos $1,2$.

Evstafij, Kommentarija k zemleopisaniju Dionisija / Per. I. P. Cvetkova [Eustathe. Commentaire du Voyage autour du monde de Denys 
le Périégète / trad. de I. P. Cvetkov], Zapiski Imperatorskogo Russkogo arkheologičeskogo obščestva [Mémoires de la Société impériale russe d'archéologie], Sankt-Peterburg, 1892, t. 6, $\mathrm{n}^{\mathrm{os}} 1,2$.

Finogenova, Svetlana Il'inična, "Nastennye rospisi i mozaičnye poly pantikapejskogo pritaneja» ["Peintures murales et sols à mosaïques du prytanée de Panticapée»], in Problemy antičnoj kul'tury [Questions de culture antique], otv. red. Gennadij Andreevič Košelenko, Moskva, Nauka, 1986, p. 205-209.

—, «Sistema rospisi pomeščenija I v. do n. è. v Germonasse» [«Système de décoration peinte d'une pièce du I ${ }^{\text {er }}$ s. av. J.-C. à Hermonassa»], Tamanskaja starina, 1 (1998), p. 13-18.

—, "Očerki istorii Germonassy po materialam raskopok poslednikh let» [Études sur l'histoire d'Hermonassa, d'après le matériel des fouilles de ces dernières années»], Drevnosti Bospora, 8 (2005), p. $422-442$.

—, "Arkhaicheskaja keramika Germonassy iz raskopok poslednikh let» ["Céramique archaïque d'Hermonassa en provenance de fouilles récentes »], Drevnosti Bospora, 9 (2006), p. 337-354.

—, "Germonassa" ["Hermonassa»], in Antičnoe nasledie Kubani [L'héritage antique du Kouban], otv. red. Grigorij Maksimovič Bongard-Levin, Vladimir Dmitrievič Kuznecov, Moskva, Nauka, 2010, t. 1, p. 511-526.

—, «K voprosu o torgovykh otnošenijakh arkhaičeskoj Germonassy» ["À propos des liens commerciaux de l'antique Hermonassa »], in S Mitridata duet veter. Bospor i Pričernomor'e v antičnosti. K 70-letiju V. P. Tolstikova [Le vent souffle du Mont Mithridate. Le Bosphore et le littoral de la mer Noire dans l'Antiquité. Pour le $70^{e}$ anniversaire de Vladimir Petrovič Tolstikov], otv. red. Denis Valer'evič Žuravlev, Oleg Leonodovič Gabelko, Moskva, Russkij Fond Sodejstvija Obrazovaniju i Nauke, Universitet Dmitrija Požarskogo, 2015, p. 90-98.

-, Otčjot o raskopkakh na territorii gorodišca Germonassa-Tmutarakan' 2017 g. [Rapport des fouilles de 2017 sur le territoire de la cité d'Hermonassa-Tmutarakan], Moskva, 2018.

Finogenova, Svetlana Il'inična, Il'ina, Tat'jana Anatol'evna, «Rezul'taty issledovanija Tamanskogo gorodišča (po materialam 2010-2013 gg.) » ["Résultats des recherches dans la cité de Taman 
(matériel des années 2010-2013) »], Arkheologičeskie otkrytija 20102013 [Découvertes archéologiques 2010-2103], Moskva, 2015, p. 431-433.

Finogenova, Svetlana Il'inična, Il'ina, Tat'jana Anatol'evna, Č́наidze, Viktor Nikolaevič, «Novejšie rezul'taty issledovanij na Tamanskom gorodišče i nekropole» "Résultats récents des explorations de la cité de Taman et de la nécropole»], $I I M B O \Lambda A$. Antičnyj mir Severnogo Pričernomor' ja [Le monde antique du littoral nord de la mer Noire], 1 (2010), p. 248-253.

Gajdukevič, Viktor Francevič, Bosporskoe carstvo [Le Royaume du Bosphore], Moskva, Izdat. Akademii Nauk SSSR, 1949.

—, "Vinodelie na Bospore» ["L'industrie vinicole dans le Bosphore»], Materialy $i$ issledovanija po arkheologii SSSR, 85 (1958), p. 352-457. IL'InA, Tat'jana Anatol'evna, "Rezul'taty issledovanij Tamanskogo gorodišča (po materialam 2005-2015 gg.)» ["Résultats des recherches dans la cité de Taman (matériel des années 20052015)»], in Aziatskij Bospor i Prikuban'e v dorimskoe vremja. Materialy Meždunarodnogo Kruglogo stola. 7-8 ijunja 2016 g. [Le Bosphore asiatique et la région du Kouban à l'époque préromaine. Matériel de la Table ronde internationale, 7 et 8 juin 2016], Moskva, Gosudarsvtennyj Istoričeskij Muzej, 2016, p. 51-56.

-, Otčjot o raskopkakh na territorii gorodišča Germonassa-Tmutarakan' 2016 g. [Rapport des fouilles de 2016 sur le territoire de la cité d'Hermonassa-Tmutarakan], Moskva, 2017.

Kel'terbaum, Daniel', Žuravlev, Denis Valer'evič, Šlotcauer, Udo, "Issledovanija v oblasti paleografii Tamanskogo poluostrova» ["Études dans le domaine de la paléographie de la péninsule de Taman»], in Drevnie èlliny meždu Pontom Evvksinskim i Meotidoj [Les Hellènes antiques entre le Pont-Euxin et la Méotide], otv. red. Denis Valer'evič Žuravlev, Udo Šlotcauer, Moskva, Istoričeskij Muzej, 2016, p. 21-28.

Kharko, Lev Petrovič, "Fragment friza s izobraženiem gigantov iz stanicy Tamanskoj» ["Fragment d'une frise avec représentation de géants de la statnitsa de Taman»], Sovetskaja arkheologija, 7 (1941), p. 81-93.

KNıpovič, Tat' jana Nikolaevna, «Ionijskaja vaza s Tamanskogo poluostrova i klazomenskij stil' v pamjatnikakh grečeskikh poselenij severnogo poberež ja Čjornogo morja» [«Un vase ionien de la 
péninsule de Taman et le style de Clazomènes dans les œuvres des colonies grecques du littoral nord de la mer Noire»], Izvestija Gosudarstvennoj Akademii Material'noj kul'tury, 15 (1927), p. 85-101.

—, «Krasnolakovaja keramika pervykh vekov našej èry iz raskopok Bosporskoj èkspedicii 1935-1940 gg. » " La céramique des premiers siècles de notre ère des fouilles de l'expédition du Bosphore des années 1935-1940»], Materialy i issledovanija po arkheologii SSSR, 25 (1952), p. 249-326.

Korovina, Anna Konstantinovna, "Vinodel'ni Germonassy" ["Complexes de vinification d'Hermonassa»], Kratkie soobščenija Instituta arkheologii An SSSR. Moskva, 191 (1987), p. 60-67.

-, Germonassa. Antičnyj gorod na tamanskom polustrove [Hermonassa. Une ville antique sur la péninsule de Taman], Moskva, Gosudarstvennyj Muzej izobrazitel'nykh iskusstv imeni A. S. Puškina, 2002.

Majко, Vadim Vladislavovič, "Khazaro-russko-vizantijskie otnošenija v seredine X v. i Krymskaja Khazarija» "Liens entre les Khazars, la Russie et Byzance au milieu du $\mathrm{X}^{\mathrm{e}}$ siècle et les Khazars de Crimée»], Stratum plus, 5 (2000), p. 236-261.

-, Srednevekovoe gorodišče na plato Tepsen'v jugo-vostočnom Krymu [Une cité du Moyen-Âge sur le plateau Tepsen' au sud-est de la Crimée], Kiev, Akademperiodika, 2004.

Miller, Aleksandr Aleksandrovič, "Tamanskaja èkspedicija Gosudarstvennoj akademii istorii material'noj kul'tury» ["Expédition de l'Académie nationale d'histoire de la culture matérielle à Taman»], Soob̌̌čenija Gosudarstvennoj akademii istorii material'noj kul'tury, 1 (1931), p. 26-29.

—, "Tamanskaja èkspedicija Gosudarstvennoj akademii istorii material'noj kul'tury v 1931» "Expédition de l'Académie nationale d'histoire de la culture matérielle à Taman en 1931 », Soobščenija Gosudarstvennoj akademii istorii material'noj kul'tury, 7-8 (1932), p. 67-68.

NikolaEva, Èmilja Jakovlevna, «Krasnolakovaja keramika so štampami s Il'ičevskogo gorodišča” "Céramique à vernis rouge estampée de la cité Il'ič̀], Kratkie soobščenija Instituta arkheologii An SSSR. Moskva, 156 (1978), p. 110-113. 
Rostovcev, Mikhail Ivanovič, Antičnaja dekorativnaja živopis' na juge Rossii: Atlas [La peinture décorative antique en Russie méridionale: Atlas], Sankt-Peterburg, Izdanije Imperatorskoj Archeologičeskoj Kommissii, 1913.

Tokntas'ev, Sergej Remirovič, Finogenova, Svetlana Il'inična, "Novye dannye o kul'te Afrodity v Germonasse» [Nouvelles données sur le culte d'Aphrodite à Hermonassa»], Hyperboreus: Studia classica, 9.1 (2003), p. 83-88.

Zeest, Iraida Borisovna, "Raskopki Germonassy» ["Les fouilles d'Hermonassa»], Kratkie soob̌̌čenija Instituta istorii material'noj kul'tury AN SSSR, 74 (1959), p. 58-63.

—, "Arkhaičeskie sloi Germonassy» [Les couches archaïques d'Hermonassa »], Kratkie soobščenija Instituta arkheologii An SSSR. Moskva, 83 (1961), p. 53-58.

—, «Vozniknovenie i pervyj rascvet Germonassy» ["Émergence et premier âge d'or d'Hermonassa»], Sovetskaja arkheologija, 4 (1974), p. 82-97.

—, «K voprosu o gorodskoj planirovke Germonassy» ["Sur la question de l'organisation urbaine d'Hermonassa»], in Istorija i kul'tura antičnogo mira [Histoire et culture du monde antique], otv. red. M. M. Kobylina, Moskva, Nauka, 1977.

Zubarev, Viktor Gennad'evič, "Aziatskij Bospor (Tamanskij poluostrov) po dannym antičnoj pis'mennoj tradicii» «Le Bosphore asiatique (La péninsule de Taman) d'après les sources de la tradition écrite antique»], Drevnosti Bospora, 2 (1999), p. 123-146. 